\title{
A gARANTIA dE CONFORMIDADE: VARIAÇÕES FRANCESAS QUANTO À PRESERVAÇÃO DAS PARTICULARIDADES NACIONAIS E À INTEGRAÇÃO COMUNITÁRIA*1
}

\section{Sébastien Pimont**}

\section{RESUMO}

Com atraso e após um vivo debate, o regulamento de 17 de fevereiro de 2005, relativo à "garantia de conformidade devida pelo vendedor ao consumidor", transpõe na França a diretiva de 25 de maio de 1999 sobre a venda e as garantias dos bens de consumo. Ela cria um novo efeito para a venda no Código de Consumo em favor apenas do consumidor: a garantia de conformidade, que se sobrepõe às ações já existentes no Direito Civil. Tal solução apresenta vantagens, como a da preservação da fisionomia civilista dos efeitos da venda (a distinção entre a garantia dos vícios ocultos e a obrigação de entrega conforme). Mas ela gera também incertezas e, além disso, inconvenientes. Enquanto a natureza da nova garantia de conformidade mal se distingue da dos vícios ocultos, sua relevância é equívoca - assegura ela, de fato, uma melhor proteção aos consumidores?

Com três anos de atraso no calendário comunitário, ${ }^{2}$ o regulamento n. ${ }^{\circ}$ 2005-136, de 17 de fevereiro de 2005, relativo à "garantia de conformidade devida pelo vendedor ao consumidor", transpõe, na França, a diretiva de 25 de maio de 1999 sobre certos aspectos da venda e das garantias dos bens de consumo. ${ }^{3}$ Ele introduz no Código de Consumo (artigo L.211-1 e seguintes) um novo efeito da venda, a "garantia de conformidade", 4 que se sobrepõe às ações do âmbito civil de que já dispõem todos os adquirentes. ${ }^{5}$

* Artigo originalmente publicado na RTD Com. 2006 p. 261 e seg., França. Tradução livre e autorizada de Felipe Rocha dos Santos (Bolsista UNIBRAL-CAPES, Giessen-UFRGS) e primeira revisão de Marcelo Boff Lorenzen (Bolsista UNIBRALCAPES, Giessen-UFRGS), revisão final da Prof. ${ }^{a} \mathrm{Dr} .{ }^{a}$ Claudia Lima Marques, UFRGS, todos do Grupo de Pesquisa CNPq "Mercosul e Direito do Consumidor".

1 O presente estudo foi concebido a partir de uma intervenção no colóquio Le droit contemporain - des particularités nationales aux défis de lintegration ("O direito contemporâneo - particularidades nacionais frente aos desafios da integração"), organizado em 13 e 14 de maio de 2005 pela Faculdade de Direito da Universidade Babes-Bolyai em Cluj-Napoca, Romênia.

** Mestre de Conferências na Faculdade de Direito de Chambéry, Universidade de Savoie. Membro do Centro de Direito Público e Privado, das Obrigações e do Consumo.

$2 \bigcirc$ artigo 11 (1) da diretiva dispõe que "os Estados membros conferem vigência às disposições legislativas, regulamentares $\mathrm{e}$ administrativas necessárias para se conformarem à presente diretiva ao mais tardar em $1^{\circ}$ de janeiro de $2002^{\prime \prime}$. Tal atraso justificou uma condenação da França pela Corte de Justiça das Comunidades Européias: CJCE, $1^{\circ}$ de julho de 2004, aff. C311/03, Commission v. France; D. 2005, Pan. p. 614, com. de C. Nourissat; RTDciv. 2005, p. 345, com. de P. Remy-Corlay.

3 JOCE, n. ${ }^{\circ} 171$ de 7 de julho de 1999, pp. 12-16. Vide La directive communautaire sur la rente, commentaire, sous la direction de $M$. $-C$. Bianca, S. Grundmann e S. Stijns, LGDJ e Bruylant, 2004

4 Além disso, ele regulamenta o que denomina "garantia comercial" e reforma o "breve prazo" do artigo 1648 do Código Civil.

5 Vide P. le Tourneau, Le contrat de zente, Dalloz, 2005, sobretudo pp. 128-134; Responsabilités des vendeurs et des fabricants, Dalloz référence, $2^{\mathrm{a}}$ ed., Dalloz, 2006, n. ${ }^{\circ} 52280 \mathrm{e} \mathrm{s.;} \mathrm{P.} \mathrm{Brun,} \mathrm{De} \mathrm{quelques} \mathrm{enseignements} \mathrm{à} \mathrm{tirer} \mathrm{de} \mathrm{la} \mathrm{transposition} \mathrm{de} \mathrm{la} \mathrm{directive} \mathrm{CE} \mathrm{du} 25$ maz 1999, RDC 2005/3, pp. 940 e s.; J. Calais-Auloy, Une nouvelle garantie pour l'acheteur : la garantie de conformité, RTDciv. 2005, pp. 701 e s.; F. Collart-Dutilleul, Sur quelques inconvénzents du noureau régime de la garantie de conformité dans la vente de meubles corporels aux 
Para os juristas franceses, tal garantia reflete apriori uma concepção insólita dos remédios oferecidos ao adquirente decepcionado com a coisa. Na verdade, ela se aplica indistintamente a todos os casos de não-conformidade da coisa ao contrato, segundo o artigo 2 da diretiva européia e o artigo 35 da Convenção de Viena sobre a Compra e Venda Internacional de Mercadorias (C.V.I.M.). ${ }^{6}$

Não obstante, o Direito Civil francês distingue os recursos que assistem ao comprador de acordo com a causa da ausência de conformidade: ${ }^{7}$ uma não-conformidade às especificações contratuais (aliud) corresponde à inexecução da obrigação de entrega conforme, enquanto a não-conformidade da coisa à sua utilidade normal (pejus) cobre-se pela garantia relativa aos vícios ocultos. Tal dualidade acarreta a aplicação de regimes distintos (especialmente no que se refere a prazos), de sorte a constituir um "dualismo" dos efeitos do contrato, em oposição ao "monismo" da diretiva.

Em razão de tais disparidades, a transposição da diretiva provocou incertezas. A escolha do corpo de texto a acolhê-la era particularmente problemática: o Código Civil e o Código de Consumo concorriam, ambos tendo, em diversos títulos, vocação a recepcionar as disposições contidas na diretiva. Em um dado momento, o governo francês aparentou inclinar-se à via mais ambiciosa: uma reforma do Código Civil, reescrevendo-se algumas de suas disposições (artigo 1641 e seguintes) aos moldes da diretiva. Para tanto, nomeou-se uma comissão, que, em um anteprojeto de lei de transposição, organizou a fusão de duas ações do Código Civil (a garantia dos vícios ocultos e a obrigação de entrega conforme) em uma só (a garantia de conformidade) ${ }^{8}$ Contudo, a pressão de certos agentes econômicos e sociais $^{9}$ fez com que vencesse a idéia de intemalizar a diretiva através do Código de Consumo - na chamada transposição "a minima": assim determinou o regulamento de 17 de fevereiro de 2005. Conseqüentemente, a economia do sistema francês assimilou um acréscimo de ações em favor do consumidor, o qual não deixou de dispor daquelas previstas a qualquer adquirente no Código Civil: além da garantia dos vícios e da obrigação de entrega conforme, passou-se a contar com a nova garantia de conformidade integrada ao Código de Consumo.

consommateurs, RDC 2005/3, pp. 921 e s.; P. Y. Gautier, Retour aux sourves: le droit spécial de la garantie de conformité emprunté aux édiles curviles, RDC 2005/3, pp. 925 e s.; A.-M. Leroyer, Conformité des biens - Transposition de la directive n ${ }^{\circ}$ 99/44, RTDciv. 2005, pp. 483 e s.; D. Mainguy, L'ordonnance du 17 férner 2005 sur la garantie de conformité: aux regrets s'ajoutent les regrets, RDC 2005/3, pp. 947 e s.; Le noureau drat: de la garantie de conformité dans la vente au consommateur, JCP E 2005, crôn. p. 630; G. Paisant, La transposition de la directive du 25 mai 1999 sur la garantie dans la vente de bien de consommation, JCP 2005, I, 1167; Contrats, conc, consom. 2005, n. ${ }^{\circ} 8-9$, pp. 7 e s.; P. Remy-Corlay, La transposition de la directive $n^{\circ} 99 / 44 \mathrm{CE}$ dans le code de la consommation, RTDciv. 2005, pp. 345 e s.; Y.-M. Serinet, $L a$ directive du 25 mai 1999 sur les garanties dans les ventes de biens de consommation : transposer 'n'est pas oser, RDC 2005/3, pp. 955 e s; $O$. Tournafond, La nouvelle garantie de conformité des consommateurs, D. 2005, crôn. p. 1557; Quelques observations sur la garantie de conformité issue de loordonnance du 17 férrier 2005 (ant. L. 211- 1 ets. c. consom.), RDC 2005/3, pp. 933 es.

6 De 6 de abril de 1980

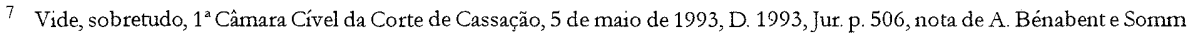
p. 242, com. de O. Tournafond; JCP E 1994, II, 526, nota de L. Leveneur. Vide, em complementação, A. Bénabent, Conformité et vices cachés dans la vente: l'éclaircie, D. 1994, orôn. p. 115.

8 Em 13 de outubro de 2000, o Ministério da Justiça criou um "grupo de trabalho encarregado de refletir sobre as modalidades de integraģão ao Direito Francés da diretiza de 25 de mais de $1999^{\circ}$ ". Esse grupo, composto de universitários, presidido pela Prof. ${ }^{a} \mathrm{G}$. Viney, forneceu um informe em que figurava um anteprojeto de lei de transposição da diretiva $n{ }^{\circ} 99-44$ sobre certos aspectos da venda e das garantias de bens de consumo, RJ com. 2003, pp. 393 es.

9 Vide, p.ex., C. de Saint-Didier, La directive $n^{\circ}$ 99/44 CE du 25 mai 1999 sur certains aspects de la zente et des garanties des biens de consommation. L'impact pour les professionnels, in Les garanties dans la vente de biens de consommation, Universidade de Santiago de Compostela, "cursos e congresos", n. ${ }^{\circ} 149,2004$, pp. 277 e s. 
$\mathrm{Na}$ França, essa transposição deu ensejo a uma forte controvérsia doutrinária. ${ }^{10}$ Prescindindo-se aqui de uma repetição dos argumentos de quem militava por uma transposição ampla e, correlativamente, por uma modificação do Código Civill, ${ }^{11}$ e de quem se dedicava a defender uma transposição a minima, ${ }^{12}$ pode-se, parece-nos, concluir que o debate não era isento de pressupostos culturais. Um dos interesses de uma transposição $a$ minima reside na preservação da atual fisionomia dos efeitos da venda, ${ }^{13}$ a qual distingue garantia de vícios ocultos e obrigação de entrega conforme. ${ }^{14}$ Às vésperas de seu bicentenário, o Código Civil fascina, e é fácil deixar-se convencer de que existe um modelo francês de efeitos da venda, um modelo que não se reduz à concepção comunitária, leia-se, internacional: a dualidade dos efeitos da venda do sistema francês no Código Civil não comporta o monismo comunitário, que acaba por escoar no Código de Consumo. ${ }^{15}$ Assim, tal defesa das "instituições do Código Cînil' somente se fez possível em razão da existência, na França, de um Código de Consumo, espécie de receptáculo natural do Direito Europeu do Consumidor: recusar-se a transpor a diretiva em seu seio implicaria negar-lhe utilidade.

Enfim, a polêmica é de tal modo acalorada que vem prolongar uma antiga disputa. Influenciada por certos autores, ${ }^{16}$ a Cour de Cassation já havia tentado unificar os efeitos da venda. ${ }^{17}$ Com esse intuito, concebeu, durante a década de 1980, uma ampla obrigação de entrega conforme, englobando os vícios ocultos: era um modelo de efeito único da venda, baseado no Direito Internacional da Compra e Venda. ${ }^{18} \mathrm{~A}$ fusão assim operada permitia que se evitasse o curto prazo da garantia dos defeitos ocultos (artigo 1648) no trato das questões de conformidade, ${ }^{19} \mathrm{e}$, sobretudo, de segurança. ${ }^{20}$ Tendo em vista que certos autores publicaram reservas, ${ }^{21}$ a jurisprudência abandonou essa posição e preferiu retomar a dualidade dos efeitos da venda. ${ }^{22}$

10 Vide, sobretudo, Les actes du colloque onganisé par Université de Paris I le 8 novembre 2002, La transposition en droit francais de la dinective européenne du 25 mai 1999 relatize à la vente, JCP E, Cahiers de droit de l'entreprise, 2003, $11{ }^{\circ} 1$

11 Vide, sobretudo, G. Viney, Quel domaine assigner à la loi de transposition de la directive européenne sur la vente, JCP 2002, I, p. 158; Retour sur la transposition de la dinecture du 25 mai 1999, D. 2002, crón. p. 3162; P. Jourdain, Transposition de la dinective sur la rente du 25 mai 1999. ne pas manquer une occasion de progrès, D. 2003, p. 4; D. Mazeaud, La parale est à la défense, D. 2003, p. 6.

12 Vide, sobretudo, G. Paisant e L. Leveneur, Quelle transposition pour la directive àu 25 mai 1999 sur les garanties dans la rente de biens de consommation ?, JCP 2002, I, p. 135; O. Tournafond, De la transposition de la directive du 25 mai 1999 à la réforme du code ciril, D. 2002, crôn, p. 2883; Transtosition de la directive de 1999 sur la garantie des consommateurs - anticle de foi ou réalisme législatif ?, D. 2003, crón. p. 427

13 Vide P. Malinvaud, Problemes de transposition de la directive en droit français, in La directive communautaire sur la vente, op. att., n. ${ }^{\circ} 133, \mathrm{p} .94$.

14 Trata-se de "conceitos clássicos sobre os quais nosso Direito positivo se constríz" ou de uma "diferenga conceitual bastante peal", a partir da qual "se estruturou nosso Direito positivo", O. Tournafond, De la transposition de la dinective du 25 mai 1999 à la réforme du code cizil, op. cit., sobretudo p. 2884

15 Vide, a título de comparação, A Ghozi, La conformité, in Faut-il recodiffer le drmit de la consommation? Org. D. Fenouillet e F. Labarthe, Economica, coleção Etudes juridiques, t. XV, 2002, p. 103, sobretudo p. 105

16 Vide, sobretudo, M. Alter, L'obligation de délizrance dans la vente de meubles corponels, Tese, LGDJ, 1972; P. le Tourneau, Conformités et garanties dans la vente d'objets mobiliers corporels, RTDcom. 1980, pp. 231 es; Droit de la responsabilité et des contrats, Dalloz, 2004/2005, n. ${ }^{\circ} 5995$ e s., sobretudo $n^{\circ} 5999$.

17 Vide, p.ex., $1^{\text {a }}$ Câmara Cível da Corte de Cassação, 20 de março de 1989, Bull cizi I, n. 140 : "a obrigą̧ão de entrirega não consiste somente em entregaro que se convencionou, mas em pố à disposizgão do adquirente uma coisa que corresponde em todos os aspectos ao fim por ele perseguida".

18 Combinadas, a C.V.I.M. (artigo 35 es.) e a Convenção de Haia de $1^{\circ}$ de julho de 1964 , relativa à Lei Uniforme sobre a venda internacional de bens móveis corpóreos (artigo 33 es.). Também se pode enxergar aí uma forma de restaurar a unidade da ação ex empto romaniste.

19 Vide P. le Tourneau, Conformités et garanties dans la vente d'objets mobiliers corporels, op. cit, sobretudo n. ${ }^{\circ} 118$ e s., pp. 217 e s.

20 Vide P. Coëffard, Garantie des izces cachés et « restonsabilité contractuelle de drot tommun », Tese, Org. P. Remy, LGDJ, coleção Faculdade de Direito de Poitiers, 2005

21 O. Toumafond, Les prétendus concours d" actions et le contrat de vente, D. 1989, crôn. p. 237.

2 Vide $1^{\text {a }}$ Câmara Civel da Corte de Cassação, 5 de maio de 1993, cit. 
A transposição a minima contribui, assim, para a preservação de uma particularidade jurídica; não obstante, consiste em uma oportunidade perdida. ${ }^{23}$ Há cerca de quarenta anos, o Direito Francês da Compra e Venda vem-se tornando complexo: o empilhamento de textos especiais e o acúmulo de decisões denotam um regime sobrecarregado. E a referida confusão suscita logicamente numerosos questionamentos: a distinção entre a garantia de vícios e a obrigação de entrega conforme vê-se longe de ser clara, e o mesmo vale para aquela entre os vícios ocultos e o erro sobre a substância. ${ }^{24}$ Enfim, a natureza e a função dos danos $\mathrm{e}$ interesses advindos da inconformidade da coisa permanecem um tanto enigmáticas. Em que pese um esclarecimento legislativo ambicioso fosse de se esperar, isso nunca ocorreu: ao contrário, em cada um desses pontos, ao adicionar uma ação suplementar, a transposição parece ter anuviado um pouco mais as soluções. ${ }^{25}$

Além disso, novas incertezas sempre surgirão, todas fundadas sobre a multiplicação das ações (três para o consumidor - duas civis e uma consumerista) que, quando da execução do contrato, tendem a satisfazer o mesmo objetivo - assegurar ao adquirente que o bem será conforme às suas expectativas. Tal profusão de ações é ainda mais inconveniente ao serem elas postas em concorrência. Conforme o artigo L.211-13 do Código de Consumo, o consumidor poderá escolher a ação que lhe pareça a mais apropriada; e, para não ter de escolher, poderá até mesmo cumulá-las. ${ }^{26}$ Logo, o risco de confusão entre os diferentes efeitos da venda será grande, ${ }^{27}$ ameaçando a clareza do Direito francês, ${ }^{28} \mathrm{e}$ pode-se, ao final, questionar se o interesse do consumidor é, de fato, atendido por um tal empilhamento de ações.

No fundo, a criação de um efeito da venda em favor apenas do consumidor - a garantia de conformidade -, acrescendo-se às ações do Código Civil, talvez não passe de uma falsa boa idéia. Pensando proteger, de uma só vez, a integridade do Código Civil e o interesse dos consumidores, o legislador provavelmente não percebeu que, embora estivesse, de um lado, sacramentando uma interpretação jurisprudencial do Código Civil - a distinção da garantia dos vícios ocultos e da obrigação de entrega conforme - de outro, não necessariamente atendia ao interesse do consumidor ao aumentar o número de recursos (de dois para três) de que dispõe.

A "garantia de conformidade"é um novo efeito da venda, cuja natureza deve ser precisada (seria autônoma frente às ações civis existentes?) (I) antes que sua relevância possa ser determinada (sua criação oportuniza uma melhor proteção aos consumidores?) (II).

23 Nesse sentido, vide B. Fages, Projet de loi de transposition de la directive 99/44 CE du 25 mai 1999, au retard s'ajoute le regret, Revue Lamy Droit civil, n. ${ }^{\circ} 9$, outubro de 2005 , pp 5 es.

24 Vide, sobretudo, D. Tallon, Emrreur sur la substance et garantie des vices dans la vente mobilière, Etude comparée des droits Francais et Anglais, in Dix ans de conférences d'agrégation, Etudes de droit commercial offertes âf. Hamel, Dalloz, 1961, pp. 437 e s.; Y.-M. Serinet, Les régimes companés des sanctions de lemeur des zices cachés et de lobligation de délizance dans la vente, Tese, Paris I, 1996 - a questão não é, no entanto, inédita; Vide L. Saignat e G. Baudry-Lacantinerie, Traité théorique et pratique de droit civil, De la vente et de léchange, Laroze, $1900, \mathrm{n}{ }^{\circ}$ 414; R. Demogue, Traité des obligations en général, soures des obligations, t. I, Rousseau, 1923, n. ${ }^{\circ} 270 ; \mathrm{R}$. Saleilles, Etude sur la théorie générale de lobligation, $3^{\mathrm{a}}$ ed., $1925, \mathrm{n}^{\circ} 212$ e s.; J. Hamel, Planiol e Ripert, Traité pratique de droit cizil français, $\mathrm{t} . \mathrm{X}$, contrats civils, première partie, $2^{\mathrm{a}}$ ed., $1956, \mathrm{n} .^{\circ} 126$ in fine.

25 Vide P. le Tourneau, Rerponsabilités des vendeurs et fabricants, op. cit, $\mathrm{n} .{ }^{\circ} 52283$.

26 Vide F. Collart-Dutilleul, RDC 2005/3, op. cit, p. 923: "o adquinente fará pleno uso dessa possibilidade de escolba, mesmo em demandas bierarquizadas, com uma prinoipal e outra subsidiána".

27 Nesse sentido, vide C. Rondey, Garantie de la conformité d'un bien au contrat: la directire du 25 mai 1999 enfin transposée', D. 2005, crôn, pp. 562 es.

28 Vide J. Ghestin, Le Code cinil en France aujourd" bui, RDC 2004/4, pp. 1152 e s., sobretudo n. ${ }^{\circ}$ e s., p. 1158. 


\section{I - Natureza}

Não se pode evitar a conclusão de que existe hoje uma ação a mais no ordenamento jurídico francês. E a análise jurídica não desmente tal impressão. De fato, a garantia (consumerista) de conformidade apresenta um grande número de pontos comuns com a garantia (civilista) de defeitos ocultos. Destarte, seus domínios rationae materiae (defeitos abrangidos) e rationae personae (os contratantes protegidos) são diferentes. Mas ambas as ações asseguram, igualmente, ao adquirente que ele receba aquilo pelo que pagou: trata-se, tecnicamente falando, de duas garantias jurídicas do interesse econômico do acordo, isto é, formas de segurança contra os riscos ocultos de não-conformidade. Essa identidade funcional não é, contudo, obra do acaso: ela advém de uma filiação romanista comum. ${ }^{29}$

A garantia de conformidade é, a priori, um efeito original da venda e apresenta, portanto, numerosas semelhanças com a garantia dos defeitos ocultos.

A - Assim como o artigo 35 da C.V.I.M. e o artigo 2 da diretiva de 25 de maio de 1999, o artigo L. 211-5 do Código de Consumo define a garantia de conformidade através de um ponto-de-vista duplo. O vendedor deve assegurar ao adquirente que o bem será " adequado ao uso habitualmente esperado de um bem semelhante" e, ao mesmo tempo, apresentará " as características definidas de comum acordo entre as partes", mostrando-se adequado "a todo uso especial' incluído no âmbito do acordo. Trata-se de duas hipóteses de não-conformidade para as quais o Direito Civil francês já designava duas ações distintas - respectivamente, a garantia dos vícios ocultos e a inexecução da obrigação de entrega conforme.

Além disso, conforme o artigo L. 211-4 do Código de Consumo, o vendedor responde também, em certas condições, por "defeitos de conformidade resultantes da embalagem, de instruçoes de montagem ou de instalação". ${ }^{30}$ Assim, enquanto o Direito Civil distingue diferentes ações conforme as causas de não-conformidade da coisa às expectativas do adquirente, o Direito do Consumidor não o faz - é uma marca de sua inspiração internacional e européia, e é também o testemunho de uma certa compreensão dos efeitos do contrato. Nessa concepção, a "lel" (artigo 1134 do Código Civil), a "economid" ou a estrutura do contrato são desenhadas pelo legislador em contemplação das expectativas legítimas do adquirente. ${ }^{31}$ Vis to que estas conduzem a uma utilidade econômica única (o que quer o adquirente é a conformidade da coisa), o contrato produz logicamente um único efeito (a garantia) que permite sua satisfação: "um interesse $=$ um efeito do contrato = uma ação". ${ }^{32}$ Por conséguinte, o aspecto objetivo (e abstrato) do vício oculto e o aspecto objetivo (e concreto) da inconformidade civil são aqui duas faces de uma mesma realidade: o conteúdo do comprometimento do vendedor. Assim, de acordo com os princípios do Código (artigo 1135), aquele não se obriga somente àquilo

2 Vide P.-Y. Gautier, Retour aux sources: le droit spécial de la garantie de conformité emprunté aux édiles curules, RDC 2005/3, pp. 925 e s.

30 Sobre a análise dos elementos da conformidade, vide P. le Tourneau, Droit de la responsabilité et des contrats, op. att, $\mathrm{n}{ }^{\circ} 5995$; Responsabilités des vendeurs..., op. cit., n. ${ }^{\circ} 52921$ (sobre a garantia de conformidade).

31 Vide, mais especificamente, J. Carbonnier, Introduction, in L'érolution contemporaine du droit des contrats, Journée René Savatier, Poitiers, 24-25 de outubro de 1985, PUF, publicação da Faculdade de Direito e Ciências Sociais de Poitiers, t. XV, 1986, pp. 29 es., sobretudo pp. 34 e 35 .

2 Vide C. Atias, L'équilibre venaissant de la vente, D. 1993, crón, p. 1; Précis élementaire de contentieux contractuel, PUAM, 2001, p. 46: "o contrato não se reduz a uma soma de obrigaçóes distintas e dissociávets. São um conjunto coeso". 
a que se dispõe expressamente no contrato (conformidade às estipulações), mas também a todas as consequêencias que a natureza do contrato impõe (conformidade à utilidade normal): o conjunto desses elementos (explícitos e implícitos) compõe, logicamente, o conteúdo do contrato. Em outras palavras, retalhada sob as exigências das expectativas do adquirente, a garantia de conformidade engloba, logicamente, elementos aos quais o Direito Civil francês confere diversas traduções.

B - Sub-intitulado "a garantia legal de conformidade", o artigo L. 211-4 do Código de Consumo dispõe que "o vendedor deve entregar um bem conforme ao contrato e responde pelos defeitos de conformidade existentes quando da entrega". Tal texto é um eco consumerista do Código Civil, segundo o qual o vendedor "tem duas obrigaçôes principais, a de entregar e a de garantir a coisa que vende" (art. 1603). A primeira parte do artigo L. 211-4 envolve, mais detidamente, a obrigação de entregar ("livrer")::3 quanto ao fato de "responder pelos defeitos de conformidade existentes quando da entregd", ele materializa o objeto da "nova" garantia. A aproximação desses dois efeitos da venda - entregar e garantir - recomenda-se, há muito tempo, pela natureza do contrato de compra e venda. De fato, no Direito Civil, a garantia "é uma conseqüêncid" natural da obrigação "que o vendedor contrata, de fazer com que o adquirente obtenha a coisa vendidd". ${ }^{34} \mathrm{Ela}$ permite desenhar com precisão a extensão do comprometimento do vendedor. ${ }^{35}$ Do mesmo modo, conforme os artigos L. 211-4 e seguintes do Código de Consumo, a noção de conformidade compõe a matéria da nova garantia, dá corpo à promessa do vendedor e representa correlativamente o interesse do contrato para o adquirente. ${ }^{36}$

Assim, a garantia do Código Civil e a do Código de Consumo são dois efeitos típicos ou naturais da venda. ${ }^{37}$ Elas compartilham uma função comum: completar, em favor do adquirente, a obrigação de "entregar", que forma o objeto ou a essência do contrato. Para tanto, ambas procedem à alocação dos riscos econômicos ligados à presença de defeitos ocultos: ${ }^{38}$ como a coisa deve ser útil ao adquirente, cabe ao vendedor suportá-los. ${ }^{39}$

Enquanto sua função é próxima, uma das diferenças entre a garantia de conformidade e a garantia dos vícios ocultos remete-se aos tipos de defeitos cobertos: ${ }^{40}$ não se poderiam

33 Como o artigo 2.1. da diretiva de 1999, o regulamento não emprega o termo "délizmer"; contudo, em Direito Civil, "liuraison" não é o mesmo que "délizrance"; sobre essa distinção, vide A. Bénabent, Les contrats spéciaux cuzils et commerziaux, Domat, coleção "droit prive", Montchrestien, $5^{2}$ ed., 2001, n. ${ }^{\circ} 183$

34 Pothier, Traité du contrat de rente, t. I, Debure l'ainé, Paris, $1781, n{ }^{\circ} 202 ;$ o fato de considerar a garantia como consequiência natural da venda, no entanto, não foi sempre admitido; vide G. May, Eléments de droit romain, $11^{\mathrm{a}}$ ed., Sirey, 1913, n. ${ }^{\circ} 150$ e n. ${ }^{\circ} 152$.

35 Vide Troplong, Le droit cizil expliqué suizant londre des articles du Code, De la vente, t. II, $5^{\text {a }}$ ed., Paris; Ch. Hingray, 1856, n. ${ }^{\circ} 544$, que descreve os efeitos da venda (entregar e garantir) como um aprimoramento da ação romanista única ex empto; vide também Guillouard, Traité de la vente do de l'échange, t. I, $2^{2}$ ed., Paris, Pedonne, $1890, \mathrm{n}{ }^{\circ} 294$ e n. ${ }^{\circ} 415$, que refere a garantia e a "entrega continuada".

36 Sobre as relações entre a noção de conformidade e a de objeto, vide A. Ghozi, La conformité, op, oit

37 São coisas naturais, no sentido de Pothier, Traité des obligations, t. I, Debure l'ainé, Paris, $1774,1 \mathrm{\circ}{ }^{\circ} 7$, "coisas que fazem parte do contrato, independententente de haverem as partes expressamente as disposto, sendo da natureza do contrato que tais coisas por este sejam encerradas e subentendidas"; Guillouard, op. cit, n. ${ }^{\circ} 296$

38 Nesse ponto, tratando-se da garantia de vícios ocultos, vide P. Coeffard, Garantie des zices cachés et responsabilité contractuelle de droit commun, Tese, op. cit, n.$^{\circ} 34$ e s.; vide, em complementação, R. Saleilles, op. cit., n. ${ }^{\circ} 213$ es.

39 Vide o que diz Troplong acerca do objeto da garantia dos vícios ocultos, op. cit., eod. loc: "a boa-fé exizga, então, que o vendedor garantisse tais qualidades essenciais" (as qualidades que tornam a coisa própria ao fim a que o adquirente se propôs) "sem as quais o objeto adquirido, no mais das veres, não passa de uma coisa sem valor".

40 Vide, em complementação, J. Calais-Auloy, De la garantie des zices cachés à la ganantie de conformité, in Mélanges Cbristian Mouly, t. II, Litec, 1998 , pp. 61 e s., sobretudo pp. 69 es. 
invocar, afirma a Cour de Cassation, os artigos 1641 e seguintes quando a coisa não estiver conforme às estipulações contratuais; ${ }^{41}$ nesse caso, é uma inexecução da obrigação de entrega que se deve sancionar. ${ }^{42}$ Contudo, tal distinção entre as "garantias" dos defeitos ocultos e de inconformidade deve ser atenuada. ${ }^{43}$

Segundo Domat e Pothier, inspiradores do Código, a garantia sanciona tanto os defeitos "que afetam a destinação normal da coisd" quanto a conformidade da coisa às qualidades prometidas, ${ }^{44}$ $\mathrm{e}$ " 0 artigo 1641, fiel à tradição romanista, admite a dualidade do defeito". ${ }^{45}$ Em outras palavras, originalmente, seu objeto compreendia tanto o vício oculto quanto a não-conformidade oculta, ${ }^{46}$ e, contrariamente ao que por vezes se pensa, essa concepção ampla dos defeitos ocultos não é desconhecida pelos autores do século XIX e do princípio do século XX. ${ }^{47}$

A leitura do Traité du contrat de vente permite explicar essa concepção. Pothier oferece uma noção funcional do defeito, ${ }^{48}$ conseqüentemente, a garantia recupera um número muito grande de hipóteses de não-conformidades ocultas, ${ }^{49}$ e seu domínio não é limitado por uma definição "patológica" do defeito como a única alteração ou anomalia da coisa. ${ }^{50} \mathrm{E}$, antes, a admissão dessa definição restritiva do vício que, ao amputar a garantia do código em boa parte de seu domínio, obrigou a "reinventar" a obrigação de conformidade na entrega. ${ }^{51} \mathrm{Em}$ sua fisionomia atual, a noção de obrigação de entrega conforme é uma criação relativamente recente, ${ }^{52}$ como um corpo estranho no sistema civil francês. ${ }^{53} \mathrm{Não}$ se saberia de outra forma sugerir que a garantia originária dos defeitos ocultos do Código Civil era, afinal, bastante próxima da garantia adaptada do modelo comunitário: ambas cobrem tanto a hipótese do vício como a da não-conformidade oculta. ${ }^{54}$

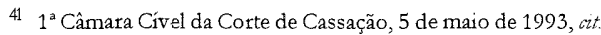

4 Lembremos que, sobre essa questão, a doutrina nunca foi verdadeitamente unânime; em favor de uma opção, vide Planiol e Ripert, Traité pratique de droit cizil français, $\mathrm{t} . \mathrm{X}$, apud Hamel, $\mathrm{n} .{ }^{\circ} 126$.

43 Vide P. Brun, Vices cachés et défauts de conformités, RDC 2005/2, pp. 350 es.; RDC 2005/3, op. cit, sobretudo p. 944

$44 \mathrm{H}$. Boucart, L'agrégation de la livraison dans la vente, Essai de théonie générale, Tese, Org. P. Rémy, LGDJ, coleção Faculdade de Direito de Poitiers, 2005, n. ${ }^{\circ} 219$ e 220

45 Vide, também, C. Accarias, Précis de droit romain, t. II, Paris, Rousseau, 1871, n. ${ }^{\circ} 909$ in fine: "os edis responsabilizam o zendedor por todas as suas declaraýzes e promessas relativamente aos zicios e is qualidades da coisa".

46 H. Boucart, of. cit, n. ${ }^{\circ} 209$

4) Vide G. Baudry-Lacantinerie e Saignat, Traité théorique et pratrque, op. cit., n. ${ }^{\circ} 417$ e n. ${ }^{\circ} 419$ : a ação em garantia concretiza-se para o uso especial da coisa incluída no círculo do acordo; ela se concretiza também para as qualidades da coisa; Guillouard, op. cit, n. ${ }^{\circ} 424$ : a garantia dos vícios ocultos concretiza-se "se o adquirente se propõe a conferir-lhe destinação especial, diferente de sua destinação normal", desđe que informe o vendedor a respeito disso; o mesmo autor estabelece, além disso, uma relação entre vícios e "qualidade leal mercante". Vide n. ${ }^{\circ} 425$ en ${ }^{\circ} 427$; Hamel apud Planiol e Ripert, Traité pratique..., op. cit, n. ${ }^{\circ} 129$.

48 Op. cit., eod loc.

4. "O vicio funcional e", em verdade, "frequentemente impossizel de distinguir do defeito de conformidade" (no sentido de inexecução da obrigação de entrega conforme). Vide $O$. Tournafond, Les prétendus concours $d^{\prime \prime}$ actions..., op. cit, sobretudo $n{ }^{\circ} 56$; e assim, segundo esse autor, a definição do artigo 1641 "não é a melbor possivel", já que "ela enfatiza o caráter funcional do vicio e deisca passar sua essência estrutural", de sorte que a distinção da não-conformidade torna-se "impraticárel", D. 1997, sum., p. 347.

50 P. Coëffard, op, att, n. ${ }^{\circ} 217$ es.

51 P. Coëffard, op, cit., n. ${ }^{\circ} 221$ e s.; H. Boucart, op. cit, n. ${ }^{\circ} 233$.

5 Segundo M. Coëffard (op, cit, n1. 223 e s.), a paternidade da "sistematização da distingấo" remonta ao autor belga De Page, ao Traité élémentaire de droit civil belge, t. IV, n. ${ }^{\circ}$ 92, 1948; no mesmo sentido, vide H. Boucart, op, cit., n. ${ }^{\circ} 235$.

53 Vide A Seriaux, Contrats cirzis, PUF, coleção "droit fondamental", 2001,n ${ }^{\circ} 21$ : o Código Civil "guaria da noção de entrega nada mais que uma concep̧ão material que a jurisprudência, por sua vez transformada em uma concep̧̧ão mais intelectual".

54 Vide H. Boucart, op. cit., $11 .{ }^{\circ} 277$ esclarecendo que uma "releitura romanista do artigo 1641 [...] mostra que a garantia já é aquela dos zicios da coisa e das qualidades prometidas pelo vendedor". 
Por outro lado, certos autores sugeriram que se abandonasse a obrigação de entrega conforme.$^{5.5}$ E é verdade que, pelos artigos 31 a $34 \mathrm{da}$ C.V.I.M., tal efeito da venda poderia facilmente ser reduzido ao simples ato material de pôr a coisa à disposição no tempo e lugar previstos - poder-se-ia excluir até mesmo a questão do "aliud grosseiro".

\section{II - Relevância}

A proximidade entre a garantia de conformidade e a garantia dos defeitos ocultos poderia incitar a fundir tais noções no Código Civil. Entretanto, o regulamento de transposição limita estritamente o domínio da garantia de conformidade, o que gera incertezas quanto ao regime de tal ação e leva a críticas sobre o método de transposição da diretiva que a consagra.

A - Seguindo os moldes do artigo $1^{\circ}$ da diretiva, os artigos L. 211-1 a L. 211-3 do Código de Consumo conferem à garantia de conformidade um domínio limitado, principalmente se comparado ao da garantia dos vícios ocultos dos artigos 1641 e seguintes do Código Civil. Ela se aplica aos "contratos de venda de bens móveis corpóreos", nos quais o Código de Consumo assimila "os contratos de venda de fornecimento de bens móveis a serem fabricados ou produridos" ${ }^{56}$ Ela consiste, assim, em ùma conseqüência da obrigação de entregar um bem corpóreo $^{57}$ e compreende "a água e o gás enquanto acondicionados em um volume delimitado ou em quantidade determinadd", mas não a "eletricidade". Esta não existe enquanto o bem for "vendido por uma autoridade de justiçd" ou "a leilão". Uma restrição como essa, diferentemente das suprareferidas, também se aplica à garantia dos vícios ocultos. ${ }^{58}$

Já o artigo L. 211-3 do Código de Consumo dispõe que "o presente capitulo é aplicável às relações contratuais entre o vendedor que age no âmbito de sua atividade profissional ou comercial e $o$ adquirente que age na qualidade de consumidor'. Tal limitação (rationae personae) do domínio da garantia legal ${ }^{59}$ explica a inclusão do texto no Código de Consumo; e ela encontra uma justificativa "natural", segundo os termos do informe remetido ao Presidente da República relativo ao regulamento de 17 de fevereiro de 2005, no fato de que "a diretiva prevê que a ação em garantia de conformidade se aplica às relaçôes contratuais entre profissionais e consumidores". 60

Impunha-se naturalmente uma transposição a minima? É verdade que a diretiva abrange, explicitamente, apenas as relações entre os "vendedores profissionais" e os adquirentes "consumidores" de "bens de consumo" (art. 1"); assim, seu objetivo é a priori assegurar uma proteção contra a não-conformidade dos bens ao contrato em favor apenas do consumidor

\footnotetext{
55 H. Boucart, op. cit, n. ${ }^{\circ} 256$ : "se não voltarmos à logica do artigo 1603 do Códrgo Cizll, com a entrega stricto sensu, de um lado, e a garantia de todos os defeitor da coisa, de outro, a desordem brotara".

56 Vide F. Labarthe e C. Noblot, Le contrat d'entreprise à l'épreure des articles L. 211-1 ets. du Code de la consommation, A propos delondonnance du 17 février 2005, JCP 2005, I, p. 168; P. Puig, Application au contrat d'entreprise de la nouvelle garantie de conformité: érolution ou récilution?, RDC 2005/3,pp. 963 es.

57 A princípio, a garantia dos vícios aplica-se a todas as vendas, independentemente do objeto: imóveis e móveis, corpóreos e incorpóreos

$\$ 8$ Para as vendas feitas pela autoridade de justiça, vide o artigo 1649 do Código Civil; de forma mais ampla, vide também a decisão do Tribunal Civel de Marselha, 25 de julho de 1927, DH 1927, p. 519

59 Como o regulamento não define "consumidor", caberá ao juiz determinar o domínio exato do texto; vide G. Paisant, estudo citado, nota $\mathrm{n}^{\circ} 5$, sobretudo $\mathrm{n}^{\circ} 23$

(1) Diário Oficial de 18 de fevereiro de 2005, pp. 2777 es.
} 
(parágrafo n."1, por exemplo). Com isso, ela pretende criar um "patamar mínimo de regras de Direito do Consumo válido independentemente do lugar de venda dos bens na comunidade" (parágrafo n." 5). Conseqüentemente, a existência de um Código de Consumo na França, ou seja, um apanhado de textos relativos à proteção do consumidor, mal deixaria escolha quanto ao domínio da transposição. ${ }^{61}$ De certo modo, é uma consideração de coerência legislativa que ditaria a amplitude desta. ${ }^{62}$

Tal demonstração não se produz sem falhas. Existem, de fato, na Europa, divergências importantes quanto à interpretação da intenção do legislador comunitário. Para alguns, em oposição à estrita concepção francesa, a diretiva sobre a venda estabelece as "fundações de um Direito Europeu das obrigações e dos contratos" ${ }^{13}$ ou "o núcleo do Direito Privado Geral na Europd". ${ }^{64}$ Tanto é assim que "a proteção do consumidor" não passa de um objetivo secundário. ${ }^{65}$ Formalmente, o objetivo da diretiva excede o artigo 95 do Tratado Constitutivo da Comunidade Européia (isto é, o estabelecimento de um mercado interno). $\mathrm{E}$ isso, ao que parece, não é assim por acaso: "tanto o Conselho quanto a Comissão", em verdade, "recusaram, a despeito de um desejo do Parlamento nesse sentido, reter o artigo 153 do Tratado (proteção do consumidor) como base juridica da diretiva". ${ }^{66}$ Ademais, deve-se notar que o texto se inspira na C.V.I.M., is to é, em uma obra bem-feita de Direito Privado Uniforme, e que um importante estudo de Direito Comparado precedeu sua redação. Mas, a despeito de tais afirmações, a intenção do legislador comunitário não é clara, ${ }^{67}$ e os argumentos entrechocam-se livremente. A ambigüidade dá licença aos Estados, cabendo a estes decidir a amplitude da transposição.

A adesão do legislador francês ao projeto de transposiçăo a minima explica-se, provavelmente, pela conjugação de diferentes argumentos; dentre eles, a vontade de proteger o regime civilista da compra e venda guarda provavelmente um lugar determinante, e a idéia de oferecer uma melhor proteção ao consumidor, presumidamente frágil, por óbvio, não se ausenta. ${ }^{68}$

B - Idealmente, o regime da garantia de conformidade deveria, portanto, ser mais favorável ao consumidor do que aquele da garantia dos vícios ocultos e da entrega conforme. Certas disposições parecem seguir essa linha, como a presunção de anterioridade do defeito, ${ }^{69}$ que livra, em certas condições, o adquirente de provar a presença do defeito anteriormente à entrega (art. L. 211-7 do Código de Consumo). ${ }^{70}$ Outras disposições pouco modificam o

S1 G. Paisant e L. Leveneur, Quelle transposition pour la directive du 25 mai 1999 sur les garanties dans la vente de biens de consommation, op. cit, sobretudo n. ${ }^{\circ} 10 \mathrm{es}$.

2 Vide G. Paisant, La définition de la conformité, JCP 2003, Cabiers de droit de l'entreprise, cit, pp. 20 e s.; A Ghozi, La conformité, op. cit.

63 Vide S. Grundmann e F. Gomez, Introduction, in I a directive communautaine sur la vente, Commentain, op, cit, sobretudo n. ${ }^{\circ} 18 \mathrm{e} \mathrm{s.,pp}$ $31 \mathrm{e}$ s. e os autores citados na nota n. ${ }^{\circ} 56$; L . Serrano, Champ d'application et définitions, in La directive communautaine sur la vente, op. cit, sobretudo n ${ }^{\circ} 6$ e autores citados na nota n.${ }^{\circ} 5$, ou, quanto à idéia segundo a qual a diretiva formaria "as fundaçóes dé um Dineito Eumpeu das Obrigagöes e dos Contratos", o autor fala de uma "opinião langamente difundida"; Hondius, Eumppean sale of goods act, p. 21

64 S. Grundmann e F. Gomez, op. cit, sobretudo n. ${ }^{\circ} 24$ e s.

6 Vide L Serrano, op cit, sobretudo n. ${ }^{\circ} 3$.

66 L. Serrano, op. sit., sobretudo n..$^{\circ} 3$.

6 Assim, desde o primeiro parágrafo (que remete ao artigo 153 do Tratado da CE), a diretiva limita seu domínio às vendas aos consumidores.

(8) Malinvaud, Problemes de transposition.., op, cit, sobretudo $\mathrm{n}^{\circ} .134$

(1) Para a douttina francesa, essa idéia não é novidade, vide Guillouard, op. cit., n. ${ }^{\circ} 451$; Troplong. op. cit, n. ${ }^{\circ} 569$

0 "Os defeitos de conformidade que aparecem em um prazo de sets meses a partir da entrega do bem presumem-se existentes no momento da entrega, salio prezzião em contrário". 
nível de proteção de que já se beneficia o consumidor, como as regras relativas às cláusulas limitativas ou elusivas de garantia (art. L. 211-17 do Código de Consumo).$^{71}$ Por fim, de uma forma surpreendente ante as ambições fixadas pela diretiva e pelo legislador, certas disposições são menos favoráveis ao consumidor que o Direito comum. Por exemplo, o artigo L. 211-10 do Código de Consumo estabelece uma hierarquia entre os remédios de que dispõe o adquirente decepcionado. ${ }^{72}$ Este pode escolher entre a "substituição e a reparação" da coisa (art. L. 211-9 do Código de Consumo); mas somente se tais soluções "forem impossíveis" ou não puderem ser postas em prática "no prazo de um mês contado da reclamação do adquirente" ou "sem maior inconveniente, levando-se em conta a natureza do bem e do uso a que ele serve", é que "o adquirente pode devolver o bem e ser restituido do preço, ou manter o bem e recuperar parte do preço". Em outras palavras, ele não pode livremente requerer a resolução do contrato ou a redução proporcional do preço; é a satisfação in natura (substituição ou reparação do bem) que vem em primeiro lugar. ${ }^{73}$ No entanto, uma tal hierarquia não existe no Direito Civil, em que ainda cabe ao adquirente apreciar o interesse econômico da coisa ${ }^{74}$ Ademais, o artigo L. 211-12 do Código de Consumo dispõe que "a ação resultante do defeito de conformidade prescreve em dois anos a contar da entrega do bem". Porém, a garantia dos vícios ocultos é encerrada em um "prazo de dois anos a contar da descoberta do vício" (artigo 1648 do Código Civil), e as ações ligadas à inexecução da obrigação de entrega conforme prescrevem em 10 ou 30 anos, conforme a natureza do ato.

É desse modo, então, que se promove na França um nível elevado de proteção dos consumidores? Consciente de tal impropriedade, o legislador instituiu uma opção em prol do consumidor. Assim, as disposições consumeristas sobre a garantia de conformidade "não privam o adquirente do direito de exercer a ação resultante dos vicios redibitórios tal como ela resulta dos artigos 1641 a 1649 do Código Civil ou uma ação totalmente diferente, de natureza contratual ou extracontratual, que legalmente se lhe reconbeçd' (art. L. 211-12 do Código de Consumo). ${ }^{75}$

A existência de uma cumulação de ações é facilmente compreendida quando elas perseguem uma finalidade diversa. Uma vez que a conformidade difere da segurança, ${ }^{76} \mathrm{O}$ adquirente agirá sob o fundamento da garantia de conformidade para obter a substituição

71 Em matéria de garantia dos vícios ocultos, os profissionais são irreversivelmente presumidos conhecedores dos vícios da coisa que eles vendem; pela aplicação dos artigos 1645 e 1150 do Código Civil, eles não podem restringir ou excluir a garantia; ademais, uma cláusula limitativa ou excludente de responsabilidade em caso de inexecução de obrigação de entrega conforme é abusiva (artigo L. 131- 1 do Código de Consumo); ela seria, assim, proibida nas vendas entre profissionais e consumidores; sobre esse último ponto, vide J. Calais-Auloy e F. Steinmetz, Drait de la consommation, $5^{\text {a }}$ ed., Dalloz, n. ${ }^{\circ} 182$ e s.

72 Vide G. Pignarre, Les droits (légaux de l'acheteur), in Les garanties dans la vente de biens de consommation, op. cit, pp. 61 e s., sobretudo pp. 66 es.

73 Como se o legislador visse nesses remédios uma forma de supra-sumo do respeito da lei do contrato; vide E. Debily, L'exécution forcée en nature des obligations contractuelles non pécuniaires, Tese, Poitiers, $2002, \mathrm{n}^{\circ} 75$ e 85.

74 Vide G. Paisant, estudo citado, nota n. ${ }^{\circ} 5$, sobretudo n. ${ }^{\circ} 41$. Tratando-se da reparação e da substituição da coisa no quadro da garantia dos vícios, vide J. Hamel apud Planiol e Ripert, Traité pratique, op. att, n. ${ }^{\circ} 135$; G. Baudry-Lacantinerie e L. Saignat, Traité theorique et pratique, op. cit, $\mathrm{n} .{ }^{\circ} 434$.

T5 $O$ informe enviado ao Presidente da República (cit.) esclarece ainda que "a possibilidade deixada ao consumidor de beneficiar se do Código Cirip" participa da "promogão de um nivel elevado de proteção dos consumidores".

76 Vide P. le Tourneau, Droit de la responsabilité et dées contrats, op. cit, n. ${ }^{\circ} 6073$; J. Calais-Auloy, Ne mélangeons plus conformité et sécurité, D 1993, arn. p. 130 
ou reparação da coisa adquirida; mas, em outro caso, ${ }^{77}$ invocará o da responsabilidade do fato dos produtos defeituosos para obter a reparação de um prejuízo sofrido em seu corpo ou em seus outros bens em razão do fato do defeito da coisa adquirida. ${ }^{78}$

No entanto, não há certeza de que, no terreno da conformidade, a execução de um verdadeiro concurso de ações entre a garantia de conformidade, a garantia dos vícios ocultos e a obrigação de entrega conforme seja de natureza a assegurar uma melhor proteção ao consumidor. Vítima de uma não-conformidade, este poderá formular duas (ou três) demandas tendentes ao mesmo resultado. Mas existirá a tentação de "misturar" os regimes na mesma demanda; isto é, aproveitar do Código Civil, por exemplo, o prazo ou a ausência de hierarquia entre os remédios e, do Código de Consumo, a presunção da anterioridade do vício. O que farão então os juízes? Defenderão o domínio das ações? Poderiam afirmar que, por exemplo, em se podendo presumir a anterioridade de um defeito no quadro da garantia de conformidade, não mais será possível fazê-lo ao invocar-se a garantia dos vícios ocultos - isto é: a presunção de anterioridade do vício somente vale a partir de 2 anos a contar da entrega.

Diante da proximidade das noções, o juiz poderia também decidir unificar os regimes. Desse modo, bastaria à Cour de Cassation definir o defeito oculto do Direito Civil (art. 1641 do Código Civil) contemplando a noção de conformidade do Direito Consumerista (artigo L. 211-5 do Código de Consumo) e, correlativamente, redefinir a minima a obrigação de entrega. Longe de ser revolucionária, tal interpretação encontraria um suporte de peso na doutrina clássica. Assim, o que o legislador não fez - simplificar o direito da compra e venda - o juiz ainda pode realizar.

Tudo isso, só por isso? As críticas que se fazem não atingem tanto o resultado da transposição, mas sim o seu método. Por quê, mais uma vez, incluir normas oriundas da transposição no Direito Civil anterior ${ }^{79}$ Compreende-se bem, à guisa de explicação, a hesitação frente ao Direito Comunitário. É evidente que este se forma de normas díspares e representa uma espécie de "corpo estranbo" ao Direito interno, e observamos que seu espírito, assombrado por preocupações exclusivamente econômicas (o bom funcionamento do mercado), fere o gênio civilista, que se alimenta das mais altas ambições ${ }^{80}$ - como, por exemplo, "assegurar uma justa reparação dos bens e das coisas" 81 ou conferir " ao exercício da liberdade natural de cada individuo

7 Por aplicação da lei n. ${ }^{\circ} 2004-1343$, de 9 de dezembro de 2004, que alterou o artigo 1386-7 do Código Civil, a lista de responsáveis pelos produtos defeituosos foi modificada: o vendedor somente é responsável se o produtor persiste desconhecido; o vendedor pode, ainda, ser acionado invocando-se os artigos 1386-1 e seguintes, se for também produtor. Na hipótese de os artigos art. 1386-1 e seguintes não puderem ser utilizados contra o vendedor, pergunta-se se a inexecução da obrigação de segurança pode ainda ser invocada, lembra-se P. Brun, Responsabilité civile extracontractuelle, Litec, 2005, n. ${ }^{\circ} 888$.

78 O artigo L. 211-11, alinea 2, dispõe que a aplicação das disposições dos artigos L. 211-9 e L. 211-10 "não obstaculiza a alocação de danos e interesses". Sobre o que podem vir a ser, em geral, tais danos e interesses (por aplicação dos artigos 1386-1, 1646, 1645, 1147 do Código Civil), vide Commentaire de l"avant-projet de loc de transposition de la directive $n^{\circ}$ 1999/44, RJ com. 2003, op. cit, sobretudo p. 403 ep. 407.

To Sob esse ponto de vista, a filosofra dessa transposição é idêntica àquela que presidiu a integração da diretiva de 1985 relativa aos produtos defeituosos: "conserzar a integralidade do sistema francês de protęão das vítimas de produtos defeituosos, simplesmente adicionando a este [... a a regras particulares do regime comunitánio", P. Remy, Regands sur le Code, Le Code civil, Livre du bicentenaire, 1804-2004, Dalloz, Litec, 2004, pp. 99 es., sobretudo p. 115

80 Vide Y. Lequette, D'une célebration à lautre (1904, 2004), in Le Code cizith un passé, un présent un avenir, Dalloz, 2004, pp. 9 e s., sobretudo p. 25.

81 A. Seriaux, Manuel de droit des successions et des libéralités, PUF, coleção "Droit fondamental", 2003, n. ${ }^{\circ} 1$ 
as restriçoes necessárias para compatibilizá-la com a dos outros". ${ }^{82}$ Tais diferenças fundamentais impedem, logicamente, que se conceba a transposição de uma diretiva como um exercício técnico irrelevante. Bem mais, se a transposição exige que se modifique uma parte do Direito Civil, é muito provável que ela se apresente como um atentado (real ou potencial) à identidade jurídica nacional.

A veneração ao Código Civil é vinculante, e é grande a tentação de buscar preservar sua originalidade e, por extensão, aquela de suas interpretações jurisprudenciais. Tão grande o é, na verdade, que existe na França um Código de Consumo que se presta a receber as normas comunitárias. ${ }^{83}$ Mas transpor, em Direito Obrigacional, não pode resumir-se a adicionar, e a preservação da integridade de uma ou outra noção civilista deve ser condicionada à manutenção da economia geral do sistema. Por outro lado, quando as novas ações adicionamse às antigas, seus domínios se recortam parcialmente e seus regimes se acavalam sem totalmente se confundirem, de sorte que o ordenamento civil pouco a pouco se transforma. Desse modo, talvez seja necessário, antes de preservar o corpo de um ou de outro fragmento do Direito nacional, assegurar-se de suas qualidades intrínsecas. Não é precisamente essa uma das apostas científicas de harmonização comunitária? Os juristas são convidados a relativizar suas categorias jurídicas nacionais, ${ }^{84}$ e essa prática, embora tenha suas restrições, ${ }^{85}$ apresentaria suas vantagens. De uma forma geral, ela incitaria, talvez, que se forjasse uma espécie de "ciência juridica européia comum", is to é, um corpo de doutrina que formasse um contraponto técnico à Europa institucional.

82 É a definição bastante kantiana do Direito Civil francês dada por C. Aubry e C. Rau, Cours de droit cizizlfrançais, t. I, $4^{a}$ ed., Marschal e Billard, Paris, $1869, \$ 22$

83 Vide P. Remy, Regard sur le Code, op. cit, sobretudo p. 115: "a última tentagäo épreservaro Códỉgo Cinil ao acolberem-se as regras comunitánias ent códigos-receptáculo, como o Código de Consumo”; P. Brun, Droit communautaire et droit français de la vente, RDC 2003,pp. 107 e s., sobretudo p. 111: "Será que defendero Código de Consumo não passa de transformá-lo em cemitério para as noģöes que näo se querem integrar à ordem juridica interna?".

84 Vide P. Remy, Ouverture du colloque sur les concepts contractuels franģais..., op. cit, sobretudo p. 6: "a doutrina francesa não pode, a meu ver, fazer ouvir sua voz particular, a menos que repense seu próprio direito segundo as categorias que não podem ser estritamente 'indígenas' ou 'autbictones"'.

कs Essencialmente metodológicas, sobre as quais vide $A$ propos de l' activité doctrinale civitiste, quelques questions dans l'air du temps, RTD civ. 2006 (a publicar). 